\title{
D-dimer and early coronary graft closure: Not so fast
}

\author{
Edward Y. Sako, MD, PhD
}

\footnotetext{
From the Department of Cardiothoracic Surgery, University of Texas Health Science Center at San Antonio, San Antonio, Tex.

Disclosures: Author has nothing to disclose with regard to commercial support.

Received for publication July 25, 2017; accepted for publication July 31, 2017; available ahead of print Sept 7, 2017.

Address for reprints: Edward Y. Sako, MD, PhD, Department of Cardiothoracic Surgery, University of Texas Health Science Center at San Antonio, Mail Code 7841, 7703 Floyd Curl Dr, San Antonio, TX 78229-3900 (E-mail: sako@uthscsa.edu).

J Thorac Cardiovasc Surg 2018;155:208-9

$0022-5223 / \$ 36.00$

Copyright $(\underset{0}{ } 2017$ by The American Association for Thoracic Surgery

http://dx.doi.org/10.1016/j.jtcvs.2017.07.056
}

In their study in this issue of the Journal, Parolari and associates ${ }^{1}$ have attempted to look at the relationship between circulating biomarkers of inflammation and short-term graft patency in patients undergoing coronary artery bypass grafting. A prospective observational study at a single institution was done with a total enrollment of 330 patients. Blood levels of a variety of inflammatory biomarkers, such as C-reactive protein, thrombin-antithrombin complex, D-dimer, and $\alpha 1$-antichymotrypsin were obtained 1 to 3 days before the operation and about 1 week after the operation. Patients were then asked to return to undergo coronary computed tomographic angiography, which occurred 15 to 21 months after their surgery. Analysis revealed that the only significant difference between those patients with patent grafts and those with 1 or more occluded grafts with regards to the biomarkers was an increased level of D-dimer at baseline in those with an occluded graft.

In assessing the significance and validity of this finding, several points need to be considered. The sample size is small, and the analysis even smaller, given that of the 330 patients initially entered into the study, only slightly more than half (179) underwent the follow-up coronary computed tomographic angiography. The short-term occlusion rate of left internal thoracic artery grafts was $6.3 \%$, and that of right internal thoracic artery grafts was $26.3 \%$, higher than in many published series. This raises questions about both the conduct of the operation, as well as the validity of the coronary computed tomographic angiographic assessment. This is acknowledged in the limitations section. ${ }^{1}$

Numerous factors, such as the technique of graft harvest, quality or extent of disease in the coronary targets, and degree of stenosis before the grafted area, are not accounted for in this analysis. This further clouds the picture, because these factors are well known to have effects on graft patency.

With regard to the specific finding, a proposed mechanism is not clear. D-dimers are specific crosslinked fibrin derivatives that are the product of plasmin-mediated fibrinolytic degradation (Figure 1). They are considered to be a

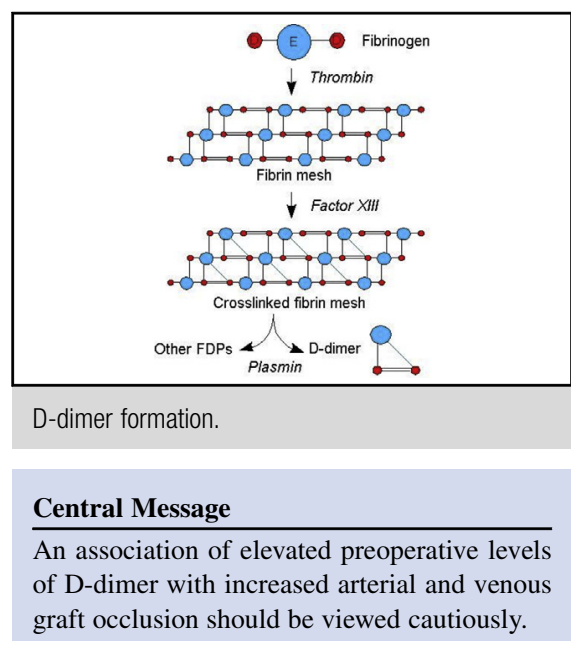

See Article page 200

marker of fibrinolytic activity and have been studied as indicators of such conditions as venous thromboembolism, atrial thrombus associated with atrial fibrillation, and aortic dissection, although with varying degrees of sensitivity and specificity. ${ }^{1-3}$ In the study of Parolari and associates, ${ }^{4}$ it is hard to understand how the preoperative levels of D-dimer
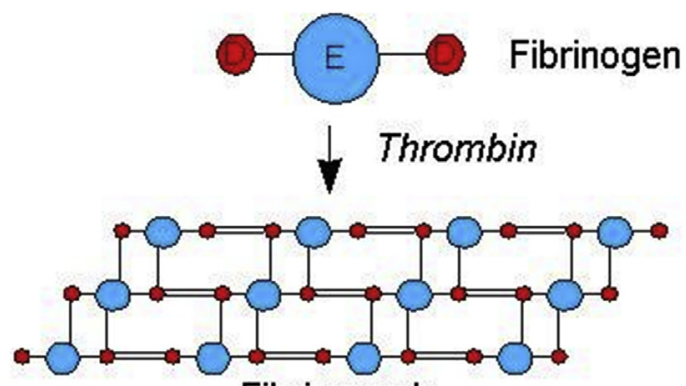

Fibrin mesh

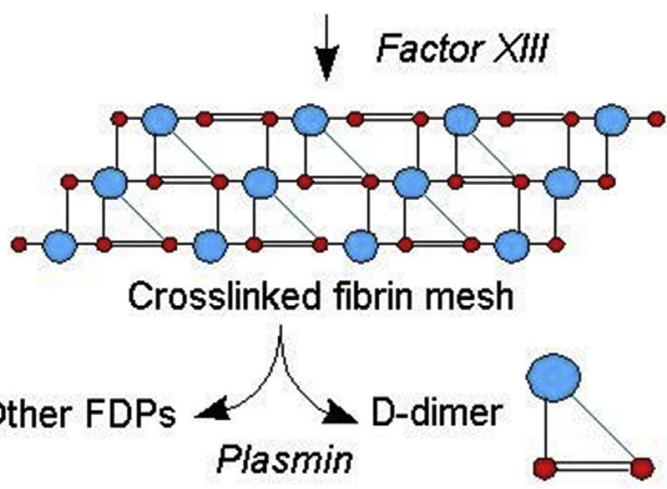

FIGURE 1. D-dimer formation. FDPs, Fibrin degradation products. 
could predict or be associated with short-term graft patency. Of note, the levels at baseline were elevated in both groups. The normal level is lower than $500 \mathrm{ng} / \mathrm{mL}$. In the "patent graft" group, levels begin at $642 \mathrm{ng} / \mathrm{mL}$; in the "occluded graft" group, at $888 \mathrm{ng} / \mathrm{mL}$. They then rise quite significantly, to more than 8 times the baseline $(5239 \mathrm{ng} / \mathrm{mL}$ and $5262 \mathrm{~mL}$, respectively) in the postoperative period. If the effect, as measured by the D-dimer levels, is thought to play a role, it would seem that the preoperative state would be overwhelmed by that of the postoperative state. In perusing all the biomarker data, no other patterns emerge. In fact, with the exception of an increase in C-reactive protein, there appears to be very little difference in all the other biomarkers, not only between the patency groups but also between the preoperative and postoperative values.
As acknowledged, the study only claims an association of the elevated biomarker level and increased short-term arterial and venous graft occlusion. One wonders, however, whether this is just a spurious result. At best, much further investigation is required, as is often the case.

\section{References}

1. Fields JM, Goyal M. Venothromboembolism. Emerg Med Clin North Am. 2008; 26:649-83. viii.

2. Wakai A, Gleeson A, Winter D. Role of fibrin D-dimer testing in emergency medicine. Emerg Med J. 2003;20:319-25.

3. Sutherland A, Escano J, Coon TP. D-dimer as the sole screening test for acute aortic dissection: a review of the literature. Ann Emerg Med. 2008; 52:339-43.

4. Parolari A, Cavallotti L, Andreini D, Myasoedova V, Banfi C, Camera M, et al D-dimer is associated with arterial and venous coronary artery bypass grafts occlusion. J Thorac Cardiovasc Surg. 2018;155:200-7.e3. 